\title{
Dissenting WITH THE Dissent: WinNIPEg CHILD aND FAMILY SERVICES (NORTHWEST AREA) V. G. (D.F.)
}

\author{
FRANÇOISE BAYLIS, PH.D.
}

On October 31, 1997, the Supreme Court of Canada rendered its decision in Winnipeg Child Services (Northwest Area) v. G. (D.F.).' The court held that its parens patriae jurisdiction did not extend to the authorization of judicial intervention on behalf of the fetus.

The Supreme Court decision was not unanimous, however. Justice Jack Major and the late Justice John Sopinka dissented from the majority opinion. On behalf of the dissent, Major J. argued that the court has the authority to confine a pregnant woman in order to prevent her from causing serious and permanent damage to her fetus, provided the following minimum threshold conditions are met: ${ }^{2}$

(1) The woman must have decided to carry the child (sic) to term.

(2) Proof must be presented to a civil standard that the abusive activity will cause serious and irreparable harm to the fetus.

(3) The remedy must be the least intrusive option.

(4) The process must be procedurally fair.

On the facts of the case before the Supreme Court, Major J. concluded that the test for judicial intervention in pregnancy had been met and that the order made by Schulman J. of the Manitoba Court of Queen's Bench, "was within the court's inherent jurisdiction in wardship matters, a subset of the parens patriae jurisdiction."

Schulman J was within his jurisdiction under parens patriae to order the respondent to refrain from consumption of intoxicating substances, and to compel the respondent to live at a place of safety until the birth of her child."

The case before the Supreme Court of Canada involved a young pregnant Aboriginal woman, D.F.G., who had suffered from solvent addiction for a number of years. During the period of her addiction, D.F.G. gave birth to three children, two of whom were

Associate Professor, Office of Bioethics Education and Research, Faculty of Medicine and Department of Philosophy, Dalhousie University. Françoise Baylis is supported by grants from Associated Medical Services Inc., Toronto and the Dean's Development Fund, Dalhousie University. Thanks are owed to Jocelyn Downie, Susan Sherwin, Gideon Koren, Michael Bolton and Carolyn McLeod.

1 Winnipeg Child Services (Northwest Area) v. G. (D.F.), [1997] S.C.J. No. 96 (QL) [hereinafter D.F.G.].

Ibid. at para. 96.

lbid. at para. 97.

Ibid. at para. 142. 
disabled, all of whom were eventually apprehended by the Winnipeg Child \& Family Services (hereafter, the Agency). In the summer of 1996, during the second trimester of D.F.G.'s fourth pregnancy, the Agency learned that D.F.G. was pregnant and that she was still addicted to solvents. The Agency sought to obtain treatment for D.F.G. for her substance abuse problem. D.F.G. indicated a willingness to accept treatment and the necessary arrangements for admission to a treatment facility were made. The day she was to be admitted, however, D.F.G. was intoxicated and refused to go. She indicated that she would seek treatment later. Her refusal set in motion a chain of legal events culminating in the Supreme Court of Canada decision.

In brief, the Agency sought a court order to compel D.F.G. to enter the treatment facility. The motions judge granted the court order and authorized D.F.G.'s confinement until the birth of her child. ${ }^{5}$ The Court of Appeal overturned this decision ${ }^{6}$ and, in turn, the Supreme Court of Canada upheld the Court of Appeal's reversal.

This difficult case raises a number of ethical issues. This essay focuses quite narrowly, however, on the dissent and its underlying assumption that judicial intervention in the lives of pregnant women with substance abuse problems is, under certain conditions, both permissible and advisable. Although the dissent has no legal force, aspects of the argument advanced by Major J. have powerful intuitive appeal. For this reason, it is important both to critically examine the dissent, paying particular attention to the first two threshold conditions, and to challenge the assumption that judicial intervention is an appropriate response to complex social-medical problems such as substance abuse in pregnancy.

\section{The Woman Must have Decided to CarRy the Child to Term}

The first threshold condition - that the woman must have decided to carry the child to term - is widely believed to establish the legitimacy of state intervention in the lives of pregnant women. In very general terms, the view is that although pregnant women have a limited right to terminate unwanted pregnancies, they do not have a right to harm developing fetuses they intend to bring to term. When a woman decides to continue a pregnancy, certain obligations arise including the obligation to prevent unnecessary avoidable harm to the child that will be born.

[I]f the pregnant woman is free to have an abortion and does not do so, then she has chosen not to avoid a situation in which she will affect the well-being of another person (the child she will bear), and in so choosing she can be deemed to have assumed responsibility for at least some aspects of the well-being of that future person.?

Winnipeg Child Services (Northwest Area) v. G.(D.F.) (1996), 138 D.L.R. (4th) 238 (Man. Q.B.). Winnipeg Child Services (Northwest Area) v. G.(D.F.) (1996), 138 D.L.R. (4th) 254 (Man. C.A.). D. Mathieu, Preventing Prenatal Harm: Should the State Intervene? 2d ed. (Dordrecht, The Netherlands: Kluwer, 1991) at 29. 
[I]t is not unreasonable to regard [the pregnant woman] as having a moral duty to the baby she is choosing to deliver.... There is no reason why the mother who has chosen to go to term should not also have a duty to prevent harm when she may reasonably do so. ${ }^{8}$

The argument continues that when the woman fails to meet her obligations, the state may legitimately intervene to protect the developing fetus' medical interests. Based on this reasoning, Justice Major writes:

I respectfully disagree with the conclusion by McLachlin J. that an order detaining a pregnant women addicted to glue sniffing for which she has rejected abortion and or medical treatment and decided to carry her child to term, would require a change to the law which cannot properly be made other than by legislation. ${ }^{9}$

In his view, "where a woman has chosen to carry a foetus to term, ... chosen to bring a life into this world, that woman must accept some responsibility for its wellbeing." 10 Further, "once the mother decides to bear the child, the state has an interest in trying to ensure the child's health."

There are a number of problems with the first threshold condition for state intervention: there is the mistaken belief that continuing a pregnancy is uniformly a matter of choice; there is the flawed assumption that a failure to obtain an abortion is evidence of such a choice; and finally there is the misguided emphasis on personal accountability which inappropriately focuses attention narrowly on women's behaviours and choices. Each of these limitations is considered in turn.

As regards the first issue, it is evident that Major J. accepts the general belief that women who remain pregnant do so by choice. With reference to the specific case before the Supreme Court, he insists that:

[T] he expectant respondent at her sole discretion could have chosen an abortion. Instead she chose to continue her pregnancy and to continue her glue sniffing. ${ }^{12}$

The respondent, on becoming pregnant for the fourth time, made the decision not to have an abortion. She chose to remain pregnant, deliver the child, and continue her substance abuse. ${ }^{13}$

The belief that women who continue their pregnancy do so as a matter of choice is not always true, however. Choice requires that there be genuine possibilities to choose among and that the decision-maker be substantially free from controlling influences. With pregnancy, frequently these preconditions for choice are not met. A brief survey

J.A. Robertson \& J.D. Schulman, "Pregnancy and Prenatal Harm to Offspring: The Case of Mothers with PKU" (1987) 17:4 Hastings Cent. Rep. 23 at 24.

, D.F.G., supra note 1 at para. 60 [emphasis added].

i'I Ibid. at para. 116.

$11 \quad$ Ibid. at para. 95.

12 Ibid. at para. 62 [emphasis added].

13 Ibid. at para. 65 [emphasis added]. 
of some of the more obvious ways in which choice about continuing a pregnancy is either constrained or precluded will help to make the point.

A clear instance where remaining pregnant may not be about choosing pregnancy is when there are problems of access to abortion because of late gestational age. Consider, for example, those situations where the woman does not know that she is pregnant at a time when it would be possible for her to choose an abortion. Some women are pregnant for months without knowing it. In some cases there is active denial on the part of the pregnant woman. In other cases there is a failure to recognize the bodily changes that are the usual symptoms of pregnancy. This is not uncommon, for example, among women with addictions who often have irregular menstrual cycles, prolonged amenorrhea or do not pay attention to the timing of their menses. ${ }^{14}$ Also, the nausea, cramps and other early symptoms of pregnancy may be mistaken for symptoms of drug withdrawal and this can further delay awareness of pregnancy. ${ }^{15}$ Delays in confirming pregnancy are relevant since terminations of pregnancy for reasons other than serious risk to the woman's life or health, or diagnosis of a serious fetal anomaly are rarely performed beyond sixteen weeks and then usually only for another eight weeks, unless there are serious risks to the woman in continuing the pregnancy.

Access to terminations can also be limited by economic, geographic and political factors. Consider, for example, the plight of a pregnant woman in Prince Edward Island who wants an abortion. Abortions are not performed in the province's referral hospitals and so the woman would have to be referred out-of-province. Her out-of-province expenses would only be paid for by the provincial health care system if certain criteria were met, including "medical necessity for the procedure." If If the criteria cannot be met and the pregnant woman does not have the financial and other resources required to get a private abortion, she would have no choice but to continue her pregnancy.

Another example to consider is the pregnant woman in an abusive relationship whose partner threatens violence should she terminate her pregnancy. Continuing a pregnancy in such circumstances is not about consenting to continued pregnancy any more than acquiescing to the demands of an armed robber is about consenting to be robbed. In such a case, continuing a pregnancy may be about choosing to maintain the relationship, or it may be about choosing to remain alive; it is not, strictly speaking, about choosing to be pregnant.

Next, there is the pregnant woman addicted to solvents, drugs or alcohol who, not infrequently, will have experienced sexual, physical or emotional abuse. She may also be poor and have experienced the harms of racism. Such women usually have fewer emotional, social and economic resources to draw on. They frequently have poor selfFetal Toxicology: A Clinician's Guide, 2d ed. (New York: Marcel Dekker Inc., 1994) 301 at 303. lbid.

Prince Edward Island, Department of Health \& Social Services, "Policy 017: Criteria for Payment of Approved Therapeutic Abortions" in Policy and Procedures Out of Province Referral Program (effective date 1 April 1995, revised and approved 23 December 1997). 
esteem, and suffer from depression as well as a heightened sense of helplessness. ${ }^{17}$ Typically they don't have a strong sense of being in control; they are unaccustomed to asserting their autonomy, having had little experience in making choices that are not directed by the wishes, needs and interests of another. When women in these types of situations find themselves pregnant, they often don't have the emotional and other resources to cope with their pregnancy and addiction alone. One coping strategy is to be passive and do nothing - a consequence of which is that the pregnancy continues without an explicit choice being made to remain pregnant. Another strategy is to remain dependent and allow others to make the decisions. In other cases, the woman's capacity to make choices may have been compromised by her addiction, so that the continuation of her pregnancy is not evidence of a choice having been made to remain pregnant.

Finally, choice can also be constrained by deeply held personal or religious beliefs. Catholicism, for example, prohibits termination of pregnancy. Thus, in important respects abortion is not among the genuine possibilities available to the devout pregnant Catholic who would prefer not to be pregnant. Considered from her perspective, she has no choice. Terminating the pregnancy is no more in the realm of the possible than is turning back the clock. For her, remaining pregnant is not about choosing pregnancy, but about being true to her faith and she may argue that her faith is not something that she chooses to adhere to, rather it is a constituent of the person. On this view, it is inaccurate to suggest that acting in a manner that is consistent with one's faith is about choosing pregnancy - one simply could not do otherwise.

The point of these examples is not to deny that many women actively choose to continue their pregnancy. For many women having children is a source of meaning and, as Carol Levine and Nancy Dubler recognize in their writings about HIV-infected women, for some women this is also a source of validation, "having babies ... may be the most reasonable and available choice, a natural outcome of all the forces in their lives, in which avenues for self-definitions and expression other than mothering are largely absent."18 While acknowledging this fact, the point is that continuing a pregnancy does not always involve a deliberate choice. Other reasons for remaining pregnant include problems of access to terminations of pregnancy, fear of assault, and oppression.

Following Susan Sherwin, in reflecting on the "choices," the "autonomous decisions" that women make, we need to think about autonomy in relational terms. Specifically, we need to attend to the context - the personal and social circumstances - in which nominally autonomous choices are made. As concerns the issue at hand, it is important to recognize that social and political conditions structure and limit the options available

J. Yaffe, J. Jenson \& M. Howard, "Women and Substance Abuse: Implications for Treatment" (1995) 13:2 Alcohol. Treat. Q. 1 at 7; A.A. Abbott, "A Feminist Approach to Substance Abuse Treatment and Service Delivery" (1994) 19:3/4 Social Work in Health Care 67 at 71 ; and P.A. King, "Helping Women Helping Children: Drug Policy and Future Generations" (1991) 69:4 Milbank Q. 595 at 600 .

18 C. Levine \& N. Neveloff Dubler, "Uncertain Risks and Bitter Realities: The Reproductive Choices of HIV-Infected Women" (1990) 68:3 Milbank Q. 321 at 323. 
to pregnant women, sometimes precluding a pregnant woman's preferred option, and sometimes eliminating all but the option of continued pregnancy. As Sherwin writes,

material restrictions, including very restricted economic resources, on-going fear of assault, and lack of educational opportunity constitute real limitations on the options available to the agent. Moreover, ... socially constructed stereotypes can reduce both society's and the agent's sense of that person's ability to act autonomously.... [As, for example, when a person has not had] the opportunity to develop the skills necessary for making the type of choice in question, the experience of being respected in her decisions, and encouragement to reflect on her own values. The society, not just the agent, is subject to critical scrutiny under the rubric of relational autonomy. ${ }^{19}$

The second problem with the initial threshold condition is with the assumption that failure to obtain an abortion is evidence of the exercise of choice. Following the statement "where a woman has chosen to carry a foetus to term, ... chosen to bring a life into this world, that woman must accept some responsibility for its well-being," Major J. stipulates that,

[i]t is not a question of a woman making a 'declaration' of her intentions. Rather, the law will presume that she intends to carry the child [sic] to term unti] such time as she indicates a desire to receive, makes arrangements for or obtains an abortion. ${ }^{20}$

This proposed test for the threshold condition is problematic. First, if indicating a desire to receive an abortion is sufficient to defeat the presumption that one intends to carry the fetus to term, then it is nearly impossible to coherently apply the test. Four words - "I want an abortion" - is all that is needed to preclude judicial intervention. Right up to the point of delivery, a pregnant woman could indicate a desire for an abortion in which case, according to the test outlined by Major J., the initial threshold condition for legitimate judicial intervention would not be met. Use of the disjunction "or" rather than the conjunction "and" means that the test does not require than an abortion be procured. Second, the more specific requirements that the woman make arrangements for or obtain an abortion as evidence that she does not intend to carry the fetus to term are also problematic. As shown above, there are many reasons why pregnant women do not get an abortion. These various reasons cannot simply be collapsed into the single reason that the woman chooses to continue her pregnancy. The mistake here is in believing that with the availability of abortion, continuing a pregnancy is an expression of choice. ${ }^{21}$

Problems with the application of the test for determining whether a pregnant woman intends to carry the fetus to term underline a problem with the choice of initial threshold conditions for which the test was developed. The underlying assumption is

S. Sherwin, "A Relational Approach to Autonomy in Health Care" in S. Sherwin, coord., Feminist Health Care Ethics Network. The Politics of Women's Health: Exploring Agency and Autonomy (Philadelphia: Temple University Press, 1998) 19 at 37.

$20 \quad$ D.F.G., supra note 1 at para. 116.

${ }^{21} \quad$ See for example H. Tristram Engelhardt Jr., "Current Controversies in Obstetrics: Wrongful Life and Forced Fetal Surgical Procedures" (1985) 151 Am. J. Obstet. Gynecol. 313. 
that the state's obligation to promote the medical interests of the developing fetus is somehow contingent upon, or a consequence of, the pregnant woman's personal choice. This assumption is clearly false. While there are certainly obligations for the pregnant woman who decides to continue her pregnancy arising from her liberty of choice and from the unique nature of the relationship between herself and her fetus, these are not themselves the source of any state obligations to the developing fetus. At most, such obligations might derive from the state's duty of care to its members. One could reasonably argue that when a live birth is foreseeable (whether by choice or circumstance), the state's duty of care can legitimately be extended to future members. As such, what matters insofar as the state's obligations are concerned is whether there will be a live birth. The woman's choice about carrying the fetus to term is only relevant in that it markedly increases the likelihood of a live birth.

The following hypothetical scenario will help to illustrate why the expectation of a live birth is the determining factor. Imagine a situation in which a woman chooses to carry her fetus to term. Assume that the woman is an HIV-infected drug user, and that her fetus is at grave risk of harm from her continued substance abuse. If, on a balance of probabilities, it was believed that her fetus would die in utero, irrespective of her wish to carry the fetus to term, would the state have a duty to intervene? Decidedly not - there is no expectation of harm to a child that will be born and so no future medical interests to protect or promote. Assuming, for the sake of argument, that judicial intervention may sometimes be legitimate, Major J. erred in his choice of initial threshold conditions. If a live birth is not foreseeable, the pregnant woman's choosing to carry the fetus to term (or not) is irrelevant.

This brings us to the final problem with the first threshold condition - it prejudicially focuses the court's attention on the pregnant woman. The condition "that the woman must have decided to carry the child to term" de facto turns the court's gaze upon the pregnant woman and away from the broader social context in which she finds herself. On this view, the woman chooses to remain pregnant and accepts certain obligations to her developing fetus; the woman acts in a manner that is inconsistent with (if not contrary to) these obligations; the woman must be detained, confined, or restrained to protect the fetus from serious and irreparable harm.

In sharp contrast, if the focus shifts away from the woman and her intentions and centres on the fact that a live birth is foreseeable - the narrative changes substantially. On this alternate view, a child will be born (by choice or circumstance); the pregnant woman and the community into which the child will be born have certain obligations; the woman's obligations include promoting the fetus' medical interests and the community's obligations are to assist (help and encourage) the pregnant woman in meeting her obligations; to this end, appropriate counselling, prenatal services, treatment and rehabilitation programs should be provided. 


\section{Proof Must be Presented to a Civil Standard

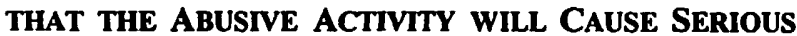 AND IRREPARABLE HARM TO THE FETUS}

According to Major J., when it is believed, on a balance of probabilities, that a pregnant woman's behaviours will harm the developing fetus, a further condition for state intervention is met. There are at least two problems with this threshold condition, however. First, it again narrowly focuses the court's attention on the pregnant woman, and second, it fails to appreciate the limits of the relevant science.

In focusing the judicial gaze exclusively on the pregnant woman, factors that contribute to fetal harm, other than the woman's actions, are inappropriately ignored. As I have argued elsewhere,

[W] ]hen attention is directed only toward the pregnant woman's behaviours and choices, the fact that 'malnutrition, violence, chaotic lives, serious matemal health problems and lack of medical care' have a significant impact on the health and well-being of the fetus is often overlooked. ${ }^{22}$

Viewed from a pragmatic perspective, the narrow focus on the pregnant woman's "abusive activity" as the cause of fetal harm is perhaps not surprising since women as causes are more tractable - more susceptible to manipulation - than other possible causes. It is important to recognize, however, that the narrow focus on pregnant women and their "choice" both to continue their pregnancy and to engage in activities that are potentially harmful to their fetuses, reflects a pragmatic rather than a principled (or even rational) choice. Arguably, this particular causal story is told because it is consistent with the aims and interests of the law in assigning responsibility to pregnant women so as to justify constraints on their autonomy and infringements on their liberty.

An alternative, equally plausible, causal story might emphasize the multifactorial nature of the problem and focus instead on an unresponsive social system as the primary cause of serious and irreparable harm to the fetus. On this account, chronic poverty, abuse and neglect, discrimination, and social disorganization might be identified as the most significant contributing causal factors. As such, the priority would not be to apprehend and detain "abusive" pregnant women, but rather to develop and implement public health practices specifically aimed at providing adequate nutrition and housing, safe living conditions, as well as access to good health care (including prenatal care), counselling, contraception, treatment, rehabilitation, and so on.

The next problem with the second condition for judicial intervention is that it presumes more certainty than science can presently offer. Major J. maintains that "the damage caused to children by serious substance abuse is well documented." ${ }^{23}$ While there is truth in this claim with respect to some teratogens, in many cases, clinical the Care of Pregnant Women: Rethinking 'Maternal-fetal Conflicts"' (1997) 156:2 Can. Med. Assoc. J. 1729 at 1731. 
judgment about the likely harmful effects of exposure to human teratogens during pregnancy is subject to much uncertainty. In this particular case, Major J. believes there to be a direct causal relationship between D.F.G.'s solvent abuse and harm to the developing fetus and, given his ultimate conclusion in the case, he obviously also believes that there is evidence to a civil standard that exposure to organic solvents during pregnancy will cause serious and irreparable harm to the fetus. However, Justice Major is mistaken both with respect to the causal relationship and the probability of fetal harm from solvent abuse.

To be sure, it must be acknowledged that it is biologically plausible that organic solvents cause fetal harm. Organic solvents are known to have a detrimental effect on the adult human brain and as the human brain develops throughout pregnancy it stands to reason that exposure to solvents during pregnancy would be detrimental to its development. Presently, however, there is no scientifically accepted empirical data establishing a direct causal relationship between solvent abuse during pregnancy and fetal harm. The Agency's expert witness, Dr. Albert Chudley, indicated (as paraphrased in the majority opinion) that "organic solvents used by glue-sniffers are neurotoxic to the brain of the foetus." ${ }^{24}$ However, Dr. Chudley acknowledged that the data was incomplete. In fact, most studies of exposure to solvents during pregnancy only suggest an association between in utero exposure to solvents and adverse outcomes such as prematurity, low birth weight, microcephaly and multiple congenital anomalies. ${ }^{25}$ Causation is difficult to prove because of the presence of numerous confounding factors as well as the difficulties in quantifying exposure. As Joyce Schneiderman notes in her work on nonmedical drug and chemical use during pregnancy:

The outcome of pregnancy in the alcohol- or drug-dependent woman depends on more that just her drug taking behaviour. The pharmacological effects are often compounded by lack of prenatal care, higher risk for other complications of pregnancy, cigarette smoking, and poor $\operatorname{diet}^{26}$

In situations where there is solvent abuse, poverty, no prenatal care, and an adverse outcome, it is relatively easy to confirm that solvent abuse is associated with fetal harm. However, as Yedidia Bentur and Gideon Koren from the Motherisk Program at the Hospital for Sick Children in Toronto report, while "it appears that organic solvents may have the potential to induce congenital defects and other pregnancy complications ... it is hard to prove or quantitate it, certainly not for solvents as a group."27

D.F.G., supra note 1 at para. 83. Dr. A. Chudley is the Head of the Section of Genetics and Metabolism at the Health Sciences Centre in Winnipeg.

G. Arnold et al., "Toluene Embryopathy: Clinical Delineation and Developmental Follow-up" (1994) 92:2 Pediatrics 216; M. Pearson, et al., "Toluene Embryopathy: Delineation of the Phenotype and Comparison with Fetal Alcohol Syndrome" (1994) 92:2 Pediatrics 211; L. WilkinsHaug \& P.A. Gabow, "Toluene Abuse During Pregnancy: Obstetric Complications and Perinatal Outcomes" (1991) 77 Obstet. \& Gynecol. 505.

Schneiderman, supra note 14 at 302.

Y. Bentur \& G. Koren, "The Three Most Common Occupational Exposures Reported by Pregnant Women: An Update" (1991) 165:2 Am. J. Obstet. Gynecol. 429 at 433. 
Secondly, even if a causal relationship could be demonstrated, the probability of harm as currently reported does not meet the standard set by Justice Major for judicial intervention. None of the available evidence shows, on a balance of probabilities, that the fetus will be seriously and irreparably harmed by solvent abuse. Current research findings on exposure to organic solvents during pregnancy are inconsistent ${ }^{28}$ both with respect to possible adverse outcomes and their probability of occurrence. ${ }^{29}$ At present, there is only one known human teratogen with a $50 \%$ probability of an adverse fetal outcome (proof to a civil standard) as a result of exposure during pregnancy and that is retinoic acid (Accutane). Indeed the very example that Justice Major uses (with somewhat of a rhetorical flourish) serves to illustrate this point and thereby to undercut his own analysis. Major J. suggests that it might be interesting to speculate on "what the results of the appeal might have been, had the state been trying to restrain a pregnant mother from taking thalidomide to deal with her morning sickness." ${ }^{30}$ To his surprise I suspect, following the reasoning outlined in the dissent, he would have had to reject judicial intervention. In discussing the standard set for exercising jurisdiction Major J. notes that,

The court's ability to intervene must ... be limited. $\boldsymbol{l}$ will only be in extreme cases, where the conduct of the mother has a reasonable probability of causing serious irreparable harm to the unborn child (sic), that a court should assume jurisdiction to intervene. ${ }^{31}$

Perhaps unbeknownst to Justice Major, with thalidomide there is only a $20 \%$ risk of fetal malformations and this risk is only when exposure occurs in days 34-50 of gestation. ${ }^{32}$ Thus, on a balance of probabilities, taking thalidomide will not cause serious and irreparable harm to the foetus.

In sum, the proper application of this threshold condition, rightfully set at a high standard, will be met in very few cases and indeed was not met in the case before the

M.-L. Lindholm, "Effects of Parental Exposure to Solvents on Pregnancy Outcome" (1995) 36:8 J. Occup. Environm. Med. 908.

29

No doubt this is due in part to the fact that many of the studies are methodologically flawed (e.g. failure to control for confounding variables such as in utero exposure to alcohol; selection bias toward children with structural or behavioural anomalies when children are identified postnatally). Ibid. at para. 123. This thetorical musing about pregnant women who, for small personal gain (e.g. relief of nausea) would willingly expose their fetuses to serious harm is offensive. As a practical matter, it is most unlikely that a woman, knowing the risks associated with the use of thalidomide during pregnancy, would elect to use the drug. Pregnant women are not self-interested monsters with no inclination for moral behaviour, intent on harming their fetuses. In fact, most pregnant women go to extreme lengths to promote fetal well-being and sometimes do so at grave risk to themselves. Further, this is not a situation analogous to that of the pregnant women with a substance abuse problem. To believe otherwise is to grossly misunderstand the nature of addiction. As noted by the American Medical Association, "In all but a few cases, taking a harmful substance such as cocaine is not meant to harm the fetus but to satisfy an acute psychological and physical need for that particular substance." Board of Trustees, American Medical Association, "Legal Interventions During Pregnancy: Court-Ordered Medical Treatments and Legal Penalties for Potentially Harmful Behavior by Pregnant Women" (1990) 264:2 J.A.M.A. 2663 at 2667. D.F.G., ibid. at para. 121 [emphasis in original].

G. Koren \& I. Nulman, "Teratogenic Drugs and Chemicals in Humans" in G. Koren ed., MaternalFetal Toxicology: A Clinician's Guide, 2d ed. (New York: Marcel Dekker Inc., 1994) 33. 
Supreme Court. Further, it is unlikely to be met in subsequent abuse cases that may be brought to lower courts in the future.

\section{Judicial INTERVENTION IN PREgnanCy}

A separate question from whether the stipulated conditions for judicial intervention are sound is whether judicial intervention to authorize incarceration or detention is an appropriate response to the problem of substance abuse during pregnancy. Major J. clearly believes so. In his view, substance abuse in pregnancy is a problem to which the law should respond - the problem is the pregnant woman and the solution to the problem is confinement. Thus far I have argued that the pregnant woman is not the problem, there are many other contributing causal factors. The question remains, however, whether judicial intervention and, in particular, confinement is an appropriate response to some other description of the problem.

For the sake of argument, assume that the first threshold condition suggested by Major J. was amended so as to only require that a "live birth is foreseeable." Further assume that the second threshold condition is properly applied such that judicial intervention would only be justified in a very limited set of cases. Under these conditions, would court-ordered confinement of the pregnant woman in order to protect fetal medical interests be morally defensible?

My own view is that even under these conditions judicial intervention is unacceptable, for several reasons. The first reason is that substance abuse during pregnancy is a complex social-medical problem - not a straightforward legal problem to be "solved" by judicial intervention. ${ }^{33}$ While there are other social-medical problems in which judicial intervention seems desirable, an obvious example being child abuse, these situations differ in important respects from substance abuse during pregnancy. Cases of child abuse involve a serious infringement of some person's legal rights. When a child is being abused or neglected his/her right to a safe and healthy environment and possibly even his/her right to life may be infringed. This infringement properly calls out for a legal response and remedy. The situation is not analogous with substance abuse during pregnancy as there is no legal entity whose rights have been infringed. Further, in child abuse situations, the abuser directly harms the child. With substance abuse during pregnancy, the woman directly harms herself and typically only in so doing does she indirectly harm the developing fetus. Finally, in cases of child abuse as contrasted with substance abuse during pregnancy, "children, unlike fetuses, can be removed from their parent's custody if they are being abused." 34 This 'moderate' response is not an option in situations involving substance abuse by pregnant women.

33 Royal Commission on New Reproductive Technologies, "Judicial Intervention in Pregnancy and Birth" Proceed with Care: Final Report of the Royal Commission on New Reproductive Technologies, vol. 2 (Ottawa: Minister of Supply and Services Canada, 1993) at 949.

34 P. King, "Helping Women Helping Children: Drug Policy and Future Generations" (1991) 69:4 Milbank Q. 595 at 601. 
The pregnancy relationship is fundamentally different from the parent-child relationship. The woman and her fetus are a "biological and social unit:"35

The fetus is in the woman's body and part of the woman's body. It is simultaneously self and not-self. Most fundamentally, however, the maternal-fetal relationship is an interconnected and interactive unit. $^{36}$

Judicial intervention in this relationship unlike judicial intervention in the parent-child relationship infringes upon women's rights to bodily integrity and self-determination. ${ }^{37}$

The second argument against judicial intervention as a response to substance abuse during pregnancy is that it is unlikely to be effective in any particular case. As noted in the majority opinion, prenatal harm from substance abuse typically occurs early in the pregnancy (possibly before the woman even knows that she is pregnant), and likely long before court intervention might be sought. As such, it is highly unlikely that courtordered detention of pregnant women with addiction problems would prevent fetal harm. In certain instances this may limit the harm to the fetus, but would at the same time visit harm upon the pregnant woman. If the goal is to prevent harm, the underlying causes of substance abuse must be addressed.

The third related argument against judicial intervention in cases of substance abuse, also noted in the majority opinion, is that it defeats the general goal of promoting the birth of healthier babies. Pregnant women who believe that the health care system is an arm of the law are unlikely to seek the prenatal care and addiction treatment they need if this exposes them to the risk of detention and forced treatment. ${ }^{38}$ As McLachlin writes for the majority,

Pregnant women suffering from alcohol or substance abuse addictions may not seek prenatal care for fear that their problems would be detected and they would be confined involuntarily and/or ordered to undergo mandatory treatment. As a result, there is a real possibility that those women most in need of proper prenatal care may be the ones who will go without and a judicial intervention designed to improve the health of the fetus and the mother may actually put both at serious health risk. ${ }^{39}$

\section{CONCLUSION}

Judicial intervention in the lives of pregnant women is an ill-founded response to an unfortunate situation that should be addressed as a health concern and not as a legal problem. To be precise, court-ordered confinement during pregnancy in an attempt to

B.K. Rothman, "When a Pregnant Woman Endangers her Fetus: Commentary" (1986) 16.1 Hastings Cent. Rep. 24 at 25.

King, supra note 34 at 614.

Rothman, supra note 35 at 25.

SOGC Clinical Practice Guidelines: Policy Statement No. 67, "Involuntary Intervention in the Lives of Pregnant Women" (1997) 19 J. Soc. Obstet. \& Gynecol. Can. 1200; see American Medical Association, supra note 30.

D.F.G., supra note 1 at para. 44. 
force changes in the pregnant woman's behaviour is unwarranted and unlikely to be effective. Arguments to the contrary rest on false beliefs and flawed assumptions.

First, there is the false belief that continuation of a pregnancy always involves a deliberate, active choice on the part of the woman. In fact, pregnancies may go to term for many reasons that do not involve choice. Second, there is the related flawed assumption that many of the behaviours that ultimately may harm the fetus, such as drug and alcohol abuse, are the result of free choices made by pregnant women who deliberately ignore medical advice, preferring instead to cause fetal harm. ${ }^{40}$ Addictions are not about choice, however. Moreover, it is important to note that in some cases, pregnant women have sought access to treatment or services for addictions only to discover that these are not available, or though available, are unhelpful because they are designed to meet the needs of male addicts ${ }^{41}$ or are denied them because they are pregnant. Third, there is the false belief that imposed intervention necessarily benefits the fetus. In specific cases there is evidence to the contrary and more generally, as health care providers well know, one must be mindful of the fact that state intervention discourages women whose fetuses may be most at risk from seeking appropriate care. Involuntary intervention in pregnancy often erodes the trust necessary for pregnant women to access health care and other services that could help to promote the birth of healthier infants.

The preferred, more effective and less intrusive response to the problem of substance abuse during pregnancy would be to develop and implement a public health program aimed at attacking the underlying social causes of addiction in a manner that empowers rather than coerces women. An ideal comprehensive public health response to the problem of substance abuse would:

declare a moratorium on legal actions against women; provide comprehensive non-coercive treatment services which include the rest of the women's family; require that programs and research address the wider problems of women's lives, including violence, hopelessness, lack of skills, relationships and concerns about children; extend programs past pregnancy so that the problem does not repeat itself; implement new models for women-specific treatment in order to reflect gender differences; include birth control options in any program so that women retain reproductive autonomy; and include education of men as integral to the problem of addiction and pregnancy. ${ }^{42}$

Major J.'s repeated references to choice about solvent addiction are perplexing. He acknowledges that D.F.G. "Was addicted to the inhalation of solvent fumes over a long period," and yet he describes her as choosing to continue glue-sniffing. See ibid. at para. 64. This suggests that he doesn't understand the nature of addiction or the many factors that make it difficult for persons with addictions to reduce their use of the addictive substance(s). It appears that D.F.G.'s sister, who testified that D.F.G. "could not resist glue sniffing," had a better understanding of addiction than the Justice; see ibid. at para. 79.

"W. Chavkin, "Drug Addiction and Pregnancy: Policy Crossroads" (1990) 80 Am. J. Public Health 483.

42 M. Harrison, "Drug Addiction in Pregnancy: The Interface of Science, Emotion and Social Policy" (1991) 8 J. Subst. Abuse Treat. 261 as paraphrased on pp. 1-2 of the Factum to the Supreme Court of Canada prepared by the Women's Health Rights Coalition. 
In closing, as Justice McLachlin writes for the majority:

This is not a story of heroes and villains. It is the more prosaic but all too common story of people struggling to do their best in the face of inadequate facilities and the ravages of addiction. ${ }^{43}$

In addressing the problem of substance abuse during pregnancy it is important to remember that most pregnant women want to promote their fetuses' well-being; unfortunately, some women lack the ability and/or the resources to do so effectively. A sound moral response to this situation is not to penalize these women by ordering them into custody (and possibly forcing treatment), but to develop and implement social policies and practices aimed at preventing avoidable prenatal harm by ensuring access to appropriate social resources. 